\title{
Research Paper \\ Marital Commitment and Relationship Quality in Fertile and Infertile Couples
}

\author{
*Saeed Shahhossiani Tajik ${ }^{1}$ (), Masoome Sayadi ${ }^{1}$, Najme Taheri ${ }^{2}$
}

1. Department of Family Psychology, Faculty of Psychology and Education, Tehran university, Tehran, Iran

2. Deptartment of Educational Psychology and Counseling, Faculty of Psychology and Educational, Tehran university, Tehran, Iran.

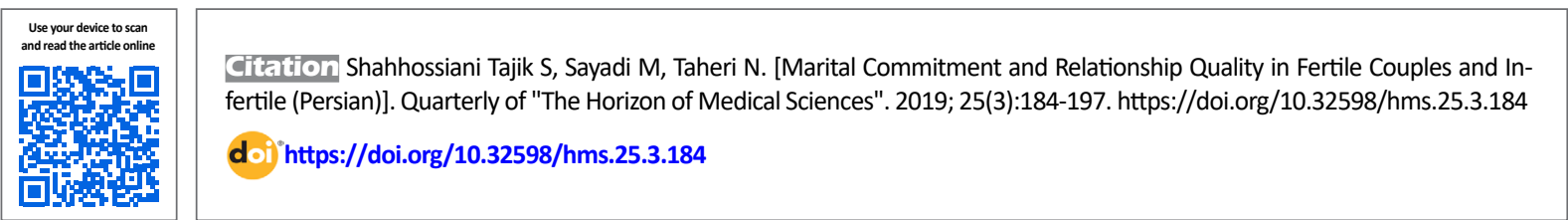

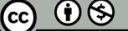

Received: 22 Jul 2018

Accepted: 23 May 2019

Available Online: $01 \mathrm{Jul} 2019$

Key words:

Marital commitment, Relationship quality, Infertility

\section{A B STRACT}

Aims Infertility is among the main problems in a marriage. It is associated with various psychological consequences, including the inability to establish a quality couple relationship as well as an unstable marital commitment. The present study aimed to investigate marital commitment and the relationship quality in fertile and infertile couples in 2016-2017.

Methods \& Materials This was an analytical cohort study. The statistical population consisted of all couples admitting to Sarem subspecialty Hospital in 2016. Two hundred people ( 96 infertile, 104 fertile) have been randomly selected as the samples. The completed the marital commitment and the relation to quality scales. After checking the normality of the data, the statistical analysis was performed using Pearson's correlation coefficient, Student t-test, and Multivariate Analysis of Variance (MANOVA).

Findings The obtained data revealed a significant positive association between marital commitment and relationship quality in fertile and infertile couples $(r=0.27$ and $r=0.18$, respectively) $(P<0.05)$. However, this association was stronger in the fertile couples, compared with the infertile ones (relationship quality and marital commitment: $\mathrm{P}<0.0121$ and $\mathrm{P}<0.0416$, respectively). Moreover, the Student t-test and MANOVA results indicated significant differences in relationship quality and marital commitment between the two groups ( $\mathrm{P}<0.0001$ and $\mathrm{P}<0.002$, respectively).

Conclusion Infertility reduces couples' commitment and negatively affects the quality of their relationships.

\section{Extended Abstract}

\section{Introduction}

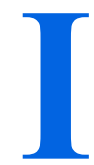

Infertility is among the major problems of marital life. It is associated with many psychological consequences, such as failing to establish highquality couple relationships and decreased commitment to marriage. In a study, the role of sexual function and relationship quality in predicting marital com- mitment were investigated. The results indicated that both variables were predictors of marital commitment; the quality of relationship was a stronger predictor of marital commitment compared to sexual function [23].

Another study indicated that couples' relationship quality could predict marital satisfaction and commitment [24]. Infertility can lead to the feelings of helplessness, conflict, frustration, severe loss of self-esteem and reduced self-confidence, withdrawal and isolation, identity crisis, feelings of

\section{* Corresponding Author:}

Shahhossiani Tajik, MSc.

Address: Department of Family Psychology, Faculty of Psychology and Education, Tehran university, Tehran,Iran.

Tel: +98 (915) 6839138

E-mail: s.shahhosseini.psy@gmail.com 
inadequacy, and the meaninglessness of life [7]. This study aimed to investigate marital commitment and relationship quality among fertile and infertile couples.

\section{Methods}

This was a cohort study. The study population consisted of all fertile and infertile couples referring to Sarem Hospital in Tehran City, Iran, in 2016. Of these, 200 samples (96 infertile and 104 fertile) were randomly recruited using Morgan Table. Data collection tools were Adams and Jones marital commitment questionnaire and Khoshkam's marital relationship quality scale.

\section{Results}

There was a significant positive relationship between marital commitment and relationship quality in fertile $(\mathrm{r}=0.27, \mathrm{P}<0.05)$ and infertile $(\mathrm{r}=0.18, \mathrm{P}<0.05)$ couples. In both groups, there was a significant positive relationship between marital commitment and its dimensions and a significant positive relationship with all relationship quality dimensions. Moreover, the relationship quality was positively and significantly correlated with all of its dimensions, and with marital commitment dimensions of moral and structural commitments; however, it was not correlated with personal commitment dimensions.

The Multivariate Analysis of Variance (MANOVA) results revealed a difference between the two groups in terms of relationship quality and its subscales (problem-solving, communication styles, spouse attention), as well as marital commitment and its subscales (personal, moral, structural).

An essential limitation of this study was the lack of matching and controlling variables, such as age, infertility duration, age of marriage, and psychological status. This was due to limitations in infertile samples. It is suggested

Table 1. Marital commitment and relationship quality of the studied couples

\begin{tabular}{|c|c|c|c|}
\hline Variable & & Mean $\pm S D$ & Student t-test Results \\
\hline \multirow{3}{*}{ Self-attention } & Fertile & $19.19 \pm 2.96$ & \multirow{3}{*}{$\mathrm{T}=3.1997, \mathrm{df}=198, \mathrm{P}=0.0290$} \\
\hline & & & \\
\hline & Infertile & $18.07 \pm 4.18$ & \\
\hline \multirow{3}{*}{ Attention to spouse } & Fertile & $28.97 \pm 3.95$ & \multirow{3}{*}{$\mathrm{T}=1.9354, \mathrm{df}=198, \mathrm{P}=0.0544$} \\
\hline & & & \\
\hline & Infertile & $27.61 \pm 5.87$ & \\
\hline \multirow{3}{*}{ Any plan for problem-solving } & Fertile & $20.06 \pm 4.76$ & \multirow{3}{*}{$\mathrm{T}=2.2956, \mathrm{df}=198, \mathrm{P}=0.0227$} \\
\hline & & & \\
\hline & Infertile & $18.44 \pm 5.22$ & \\
\hline \multirow{3}{*}{ Communication styles } & Fertile & $54.17 \pm 8.95$ & \multirow{3}{*}{$T=2.019, d f=198, P=0.0448$} \\
\hline & & & \\
\hline & Infertile & $51.02 \pm 12.90$ & \\
\hline \multirow{3}{*}{ Relationship quality } & Fertile & $122.74 \pm 17.01$ & \multirow{3}{*}{$\mathrm{T}=2.5323, \mathrm{df}=198, \mathrm{P}=0.0121$} \\
\hline & & & \\
\hline & Infertile & $115.16 \pm 24.87$ & \\
\hline \multirow{3}{*}{ Personal commitment } & Fertile & $56.38 \pm 3.58$ & \multirow{3}{*}{$\mathrm{T}=34.3306, \mathrm{df}=198, \mathrm{P}=0.0001$} \\
\hline & & & \\
\hline & Infertile & $38.44 \pm 3.81$ & \\
\hline \multirow{3}{*}{ Moral commitment } & Fertile & $38.20 \pm 3.31$ & \multirow{3}{*}{$\mathrm{T}=3.4765, \mathrm{df}=198, \mathrm{P}=0.0342$} \\
\hline & & & \\
\hline & Infertile & $38.44 \pm 3.81$ & \\
\hline \multirow{3}{*}{ Structural commitment } & Fertile & $39.44 \pm 3.83$ & \multirow{3}{*}{$\mathrm{T}=2.6603, \mathrm{df}=198, \mathrm{P}=0.0398$} \\
\hline & & & \\
\hline & Infertile & $39.04 \pm 4.72$ & \\
\hline \multirow{3}{*}{ Marital commitment } & Fertile & $134.07 \pm 5.24$ & \multirow{3}{*}{$T=6.3301, d f=198, P=0.0416$} \\
\hline & & & \\
\hline & Infertile & $133.80 \pm 6.31$ & \\
\hline
\end{tabular}


Table 2. Relationship between marital commitment and relationship quality and their dimensions in the fertile couples

\begin{tabular}{|c|c|c|c|c|c|c|c|c|c|}
\hline $\begin{array}{l}\frac{\delta}{\overline{0}} \\
\frac{\overline{0}}{\overline{0}} \\
\frac{D}{n}\end{array}$ & 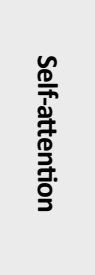 & 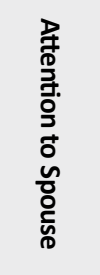 & 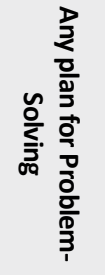 & 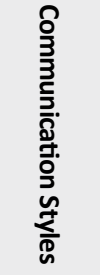 & 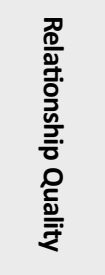 & $\begin{array}{l}\frac{7}{0} \\
\frac{1}{1} \\
\frac{0}{3} \\
\frac{0}{2} \\
\frac{0}{3} \\
3 \\
\frac{3}{7} \\
\frac{7}{3} \\
\frac{1}{2}\end{array}$ & $\begin{array}{l}3 \\
\frac{3}{0} \\
\frac{0}{2} \\
\frac{0}{3} \\
3 \\
3 \\
\frac{7}{3} \\
\frac{0}{7}\end{array}$ & 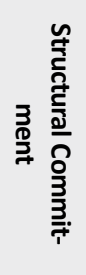 & 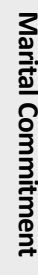 \\
\hline $\begin{array}{l}\text { Attention to } \\
\text { spouse }\end{array}$ & $0.66^{*}$ & 1 & - & - & - & - & - & - & - \\
\hline $\begin{array}{l}\text { Any plan for } \\
\text { problem-solving }\end{array}$ & $0.58^{*}$ & $0.58 *$ & 1 & - & - & - & - & - & - \\
\hline $\begin{array}{l}\text { Communication } \\
\text { styles }\end{array}$ & $0.53^{*}$ & $0.62 * *$ & $0.69 *$ & 1 & - & - & - & - & - \\
\hline $\begin{array}{l}\text { Relationship } \\
\text { quality }\end{array}$ & $0.74^{*}$ & $0.81^{*}$ & $0.83^{*}$ & $0.92^{*}$ & 1 & - & - & - & - \\
\hline $\begin{array}{l}\text { Personal commit- } \\
\text { ment }\end{array}$ & 0.03 & 0.08 & 0.06 & 0.01 & 0.05 & 1 & - & - & - \\
\hline $\begin{array}{l}\text { Moral commit- } \\
\text { ment }\end{array}$ & $0.28^{*}$ & $0.22 * *$ & $0.28 *$ & $0.35^{*}$ & $0.35^{*}$ & $0.30 * *$ & 1 & - & - \\
\hline $\begin{array}{l}\text { Structural com- } \\
\text { mitment }\end{array}$ & $0.20^{*}$ & $0.25^{*}$ & $0.18^{* *}$ & $0.18^{* *}$ & $0.23^{*}$ & $0.29 * *$ & $0.14^{* *}$ & 1 & - \\
\hline $\begin{array}{l}\text { Marital commit- } \\
\text { ment }\end{array}$ & $0.20^{* *}$ & $0.18^{* *}$ & $0.23^{* *}$ & $0.22^{* *}$ & $0.27^{* *}$ & $0.28^{* *}$ & $0.54^{*}$ & $0.64^{*}$ & 1 \\
\hline$* \mathrm{P}<0.01 ; * * \mathrm{P}<0.05$ & & & & & & & \multicolumn{3}{|c|}{$\begin{array}{l}\text { Quarterly of } \\
\text { The Horizon of Medical Sciences }\end{array}$} \\
\hline
\end{tabular}

Table 3. Relationship between marital commitment and relationship quality and their dimensions in infertile couples

\begin{tabular}{|c|c|c|c|c|c|c|c|c|c|}
\hline 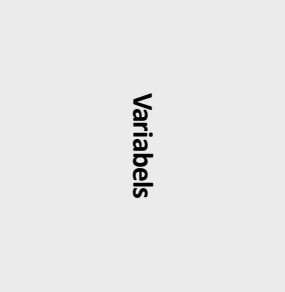 & 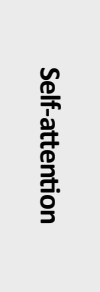 & 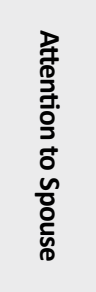 & 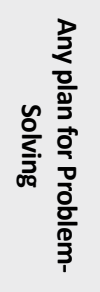 & 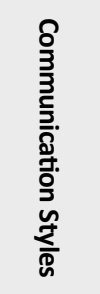 & 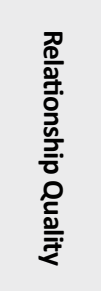 & 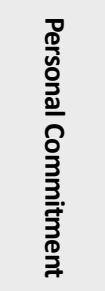 & $\begin{array}{l}3 \\
\frac{3}{0} \\
\frac{0}{2} \\
0 \\
3 \\
3 \\
\frac{1}{7} \\
\frac{1}{2} \\
\frac{1}{7}\end{array}$ & 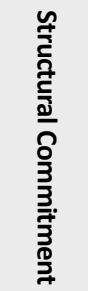 & 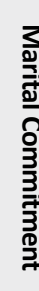 \\
\hline Attention to spouse & $0.62^{*}$ & 1 & - & - & - & - & - & - & - \\
\hline $\begin{array}{c}\text { Any plan for problem- } \\
\text { solving }\end{array}$ & $0.60^{*}$ & $0.6^{*}$ & 1 & - & - & - & - & - & - \\
\hline Communication styles & $0.50^{*}$ & $0.62^{*}$ & $0.74^{*}$ & 1 & - & - & - & - & - \\
\hline Relationship quality & $0.74^{*}$ & $0.83^{*}$ & $0.83^{*}$ & $0.90^{*}$ & 1 & - & - & - & - \\
\hline Personal commitment & 0.07 & 0.14 & 0.06 & 0.09 & 0.08 & 1 & - & - & - \\
\hline Moral commitment & $0.23^{*}$ & $0.20^{*}$ & $0.25^{*}$ & $0.35^{*}$ & $0.30 *$ & $0.30 *$ & 1 & - & - \\
\hline Structural commitment & $0.26^{*}$ & $0.18 *$ & $0.18^{* *}$ & $0.28^{*}$ & $0.23 *$ & $0.29 * *$ & $0.17^{* *}$ & 1 & - \\
\hline Marital commitment & $0.23^{* *}$ & $0.13^{* *}$ & $0.21^{* *}$ & $0.20 * *$ & $0.18^{* *}$ & $0.23 * *$ & $0.47^{*}$ & $0.59^{*}$ & 1 \\
\hline $\mathrm{P}<0.01 ; * * \mathrm{P}<0.05$ & & & & & & & $\begin{array}{l}\text { Quart } \\
\text { The H }\end{array}$ & of $\mathrm{M}$ & ᄃ \\
\hline
\end{tabular}


that future studies be conducted with peer groups regarding infertility duration, age of marriage, and psychological health. Additionally, repeating the research using similar population but from different cultural backgrounds can help to improve the theoretical richness and the generalization of the present study results. Furthermore, it is recommended that a relationship enrichment program be organized for infertile couples with the participation of family specialists and counselors.

\section{Conclusion}

The problem of infertility in marital life has adverse effects on other psychological dimensions of couples, including marital commitment and relationship quality; thus, it challenges their lives. Such unpleasant consequences can be avoided by psychological interventions in this group.

\section{Ethical Considerations}

\section{Compliance with ethical guidelines}

This study was extracted from an approved proposal (No.2300950517) provided for Sarem Hospital.

\section{Funding}

This research did not receive any specific grant from funding agencies in the public, commercial, or not-forprofit sectors.

\section{Authors' contributions}

Conceptualization, methodology, software, investigation, resources, writing, review and editing by Saeed Shahhossiani Tajik (contribution rate $=60 \%$ ); collaborate on the project and problem statement by Najme Taheri (contribution rate $=20 \%$ ); collaborate on the project, data collection and resources by Masoome Sayadi (contribution rate $=20 \%$ ).

\section{Conflicts of interest}

The authors declared no conflict of interest.

\section{Acknowledgements}

The authors would like to thank Dr. Masoud. Gholamali Lavasani (Associate Professor, Faculty of Psychology, University of Tehran) and Dr. Gholamreza Hajati (Assistant Professor, Sarem Hospital) for their valuable cooperation. 
This Page Intentionally Left Blank 


\title{
تعهد زناشويى و كيفيت ارتباط در زوجين بارور و نابارور
}

\author{
"سعيد شاهحسينى تازيك' (1) معصومه صيادى'، نجمه طاهرى'

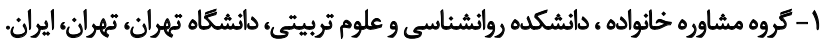

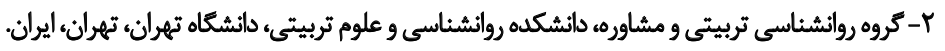

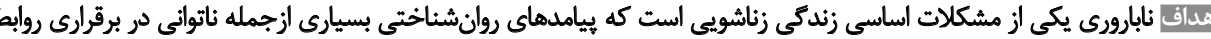

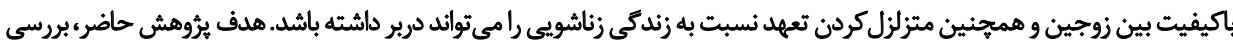

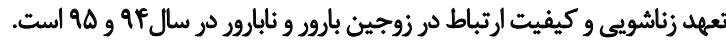

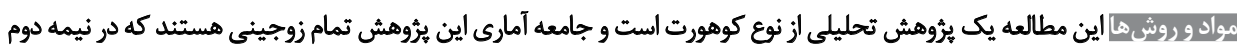

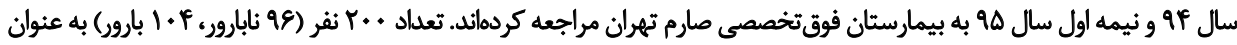

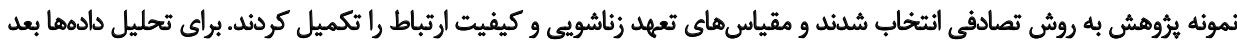

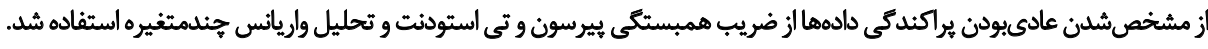

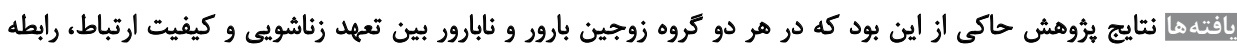

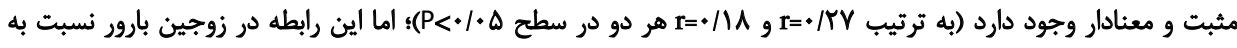

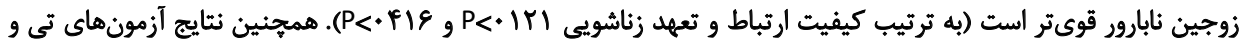

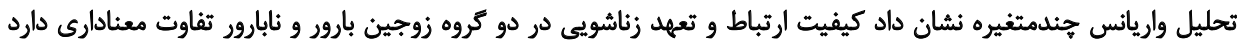

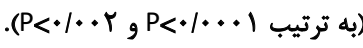

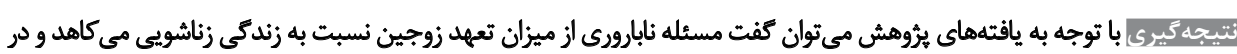

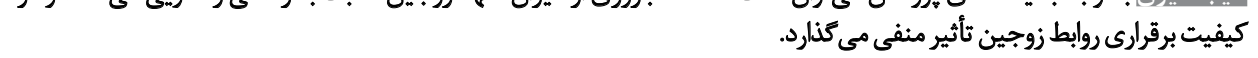

\author{
تاريخ دريافت: آT تير TaV

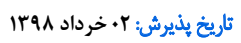

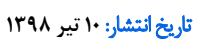

همجنين يزؤهش ها نشان دادهاند نابارورى موجب ضعف شخصيت

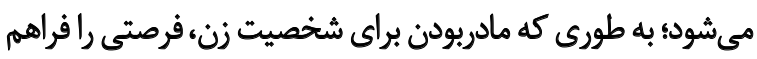

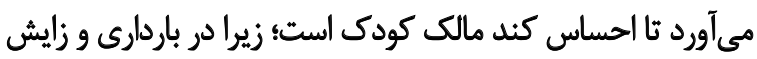

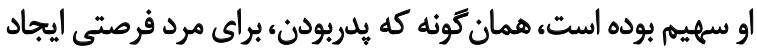

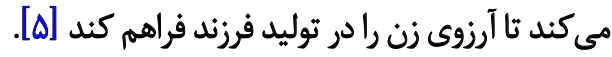
نابارورى ممكن است به دليل فشارهايى كه از لحاظ روانى به

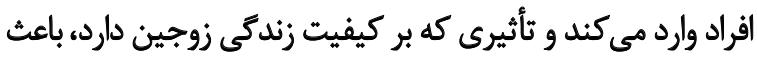

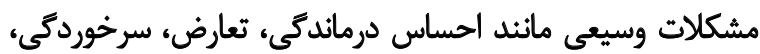
افت شديد عزت نفس و كاهش اعتمادبهنفس، كنارهكيرى و انزوا،

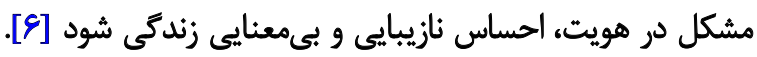

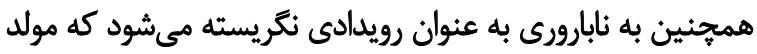

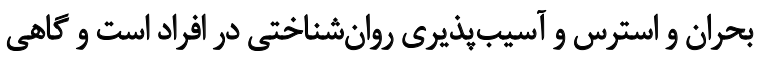

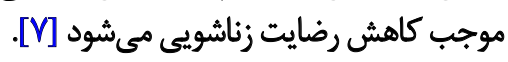

مقدمه

باروزى و توليدمثل اساس زندكى انسان و يكى از اصول

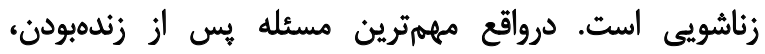

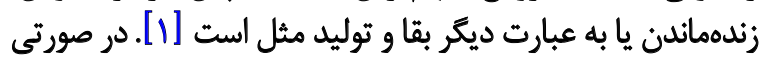

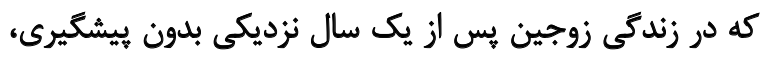

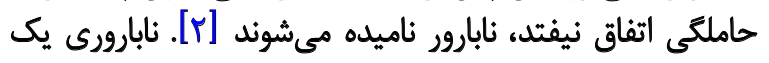

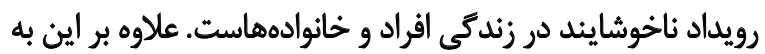

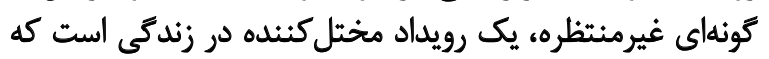

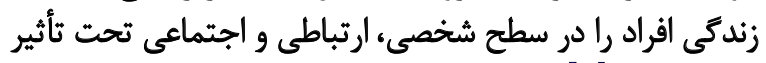

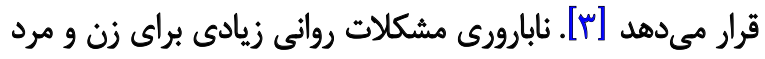

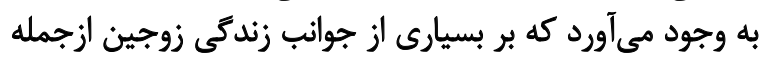

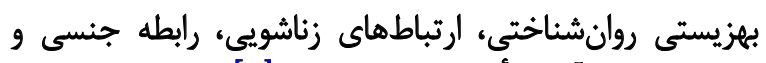

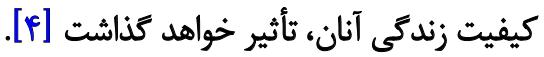


شاخص واحدى مفهومسازى شدهائد [•r] كيفيت ارتباط زوجين،

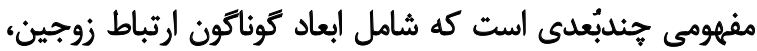

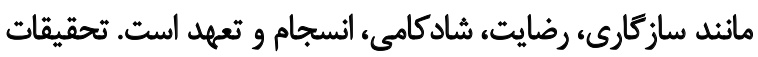

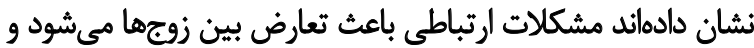

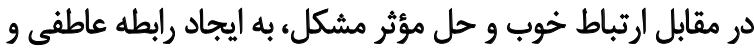

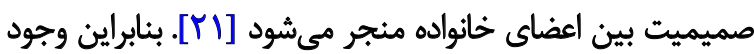

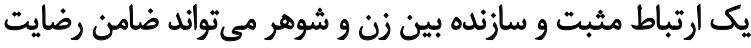

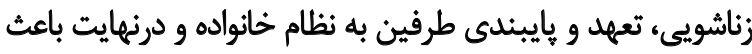

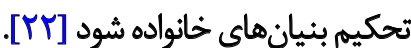

ايروهش هاى مختلفى در زمينه ارتباط بين تعهد زناشويى وكيفيت

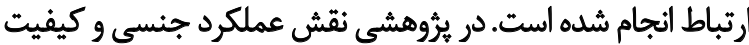

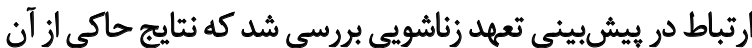

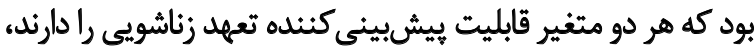

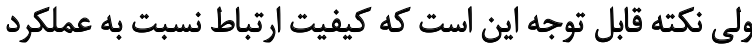

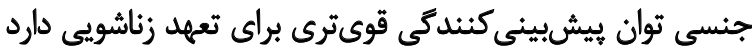

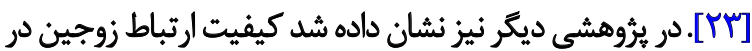

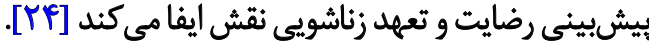

با بئكه نقش تعهد زناشويى و كيفيت ارتباط به عنوان عوامل مهرم

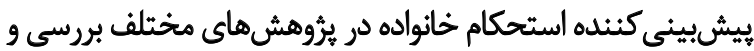

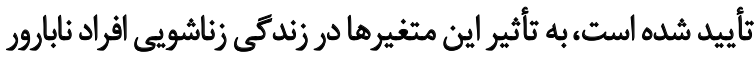

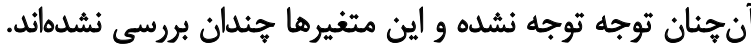

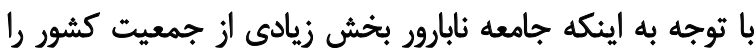

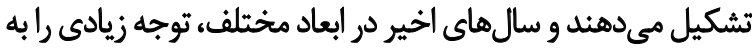

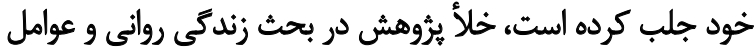

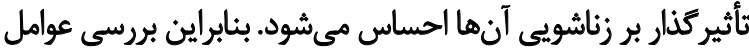

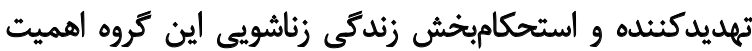

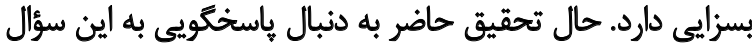

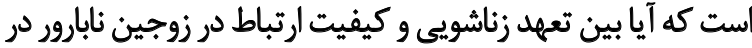
مقايسه با زوجين بارور ايرانى تفاوتى وجود داري؟

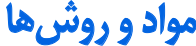

روش ءثوهش حاضر تحليلى از نوع كوهورت است (كروه كوهورت

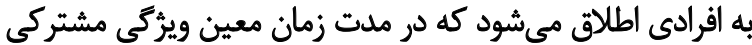

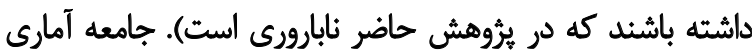

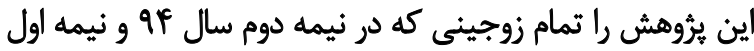

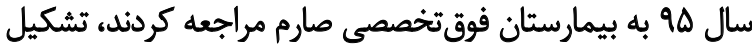

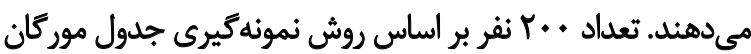

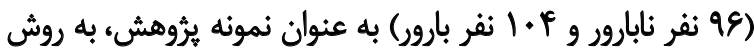

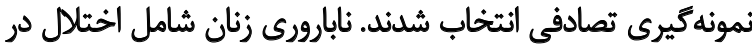

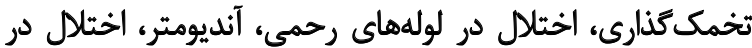

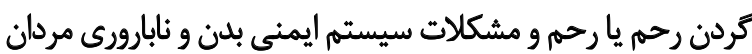

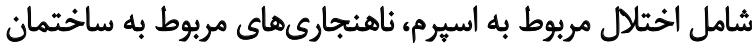
بدن و ديكر موارد جون انزال زودرس و عوامل نابارورى مشترك در مرئ
هنكامى كه بارورى به شكل ناخواسته به تأخير مى افتد يا با شكست

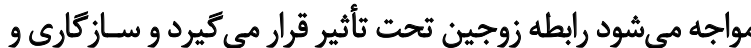

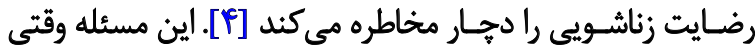

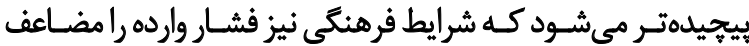

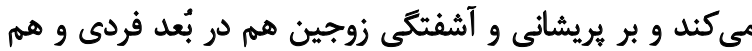
روابط دونفره مى افزايد [9].

در مرحله جفت كيرى و ازدواج يكى از مهمترين وظايف ارتبـاطي

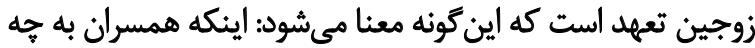

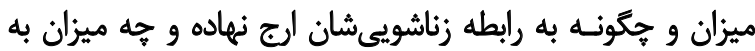

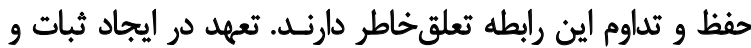

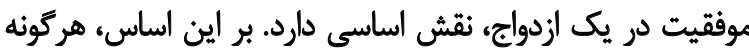

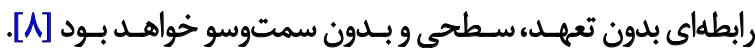

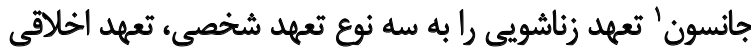

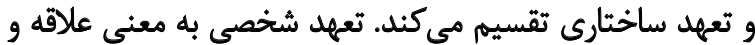

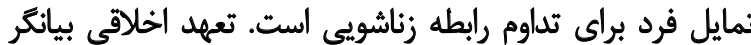

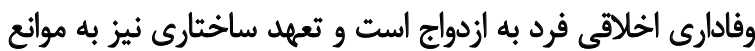

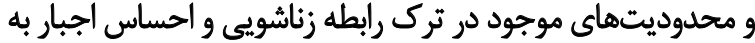

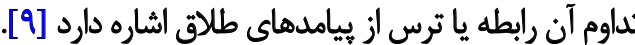
تحقيقات نشان داداند در مواردى كه زوجين با مسئله نابارورى

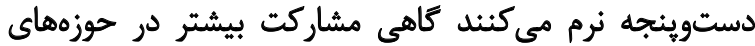

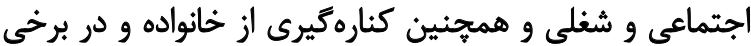

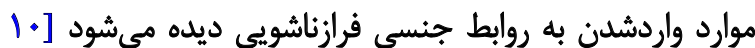

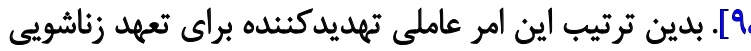

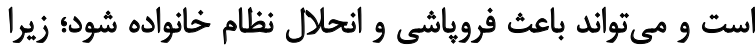

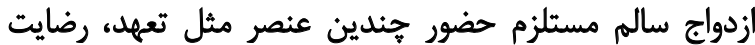

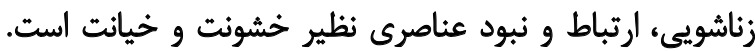

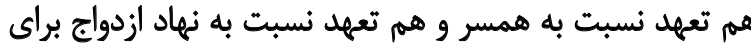

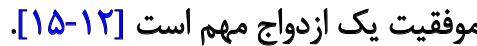

تعهل زناشويى، به عنوان قوىترين و ويايسدارترين عامـل

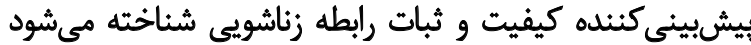

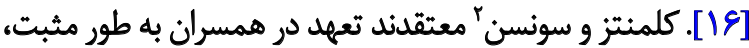

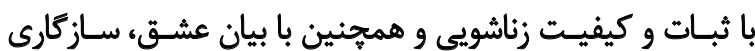

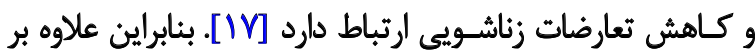

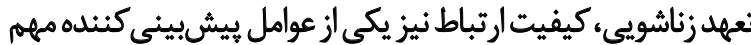

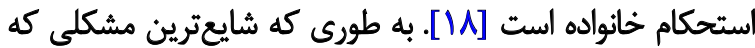

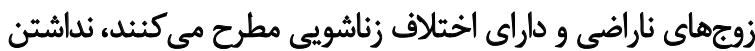

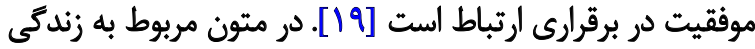

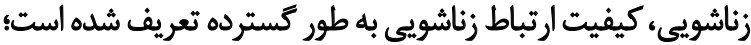

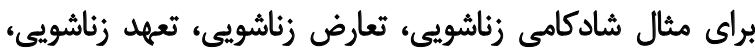

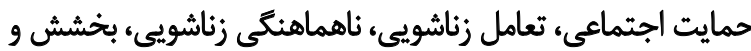

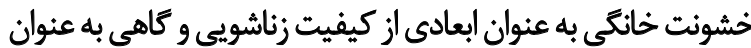

1. Johnson

2. Clements, Swensen 
حاضر به روش آلفاى كرونباخ 9 /1 به دست آمد. يرسشنامه كيفيت ارتباط زوجين

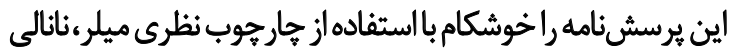

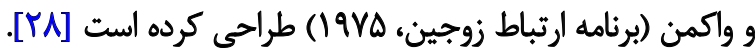

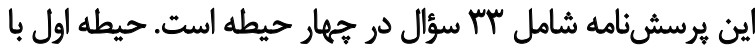

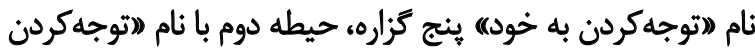

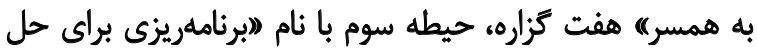

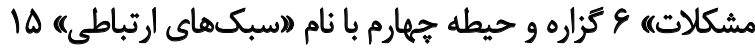

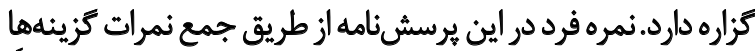

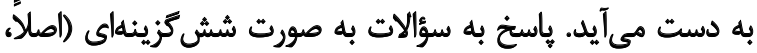

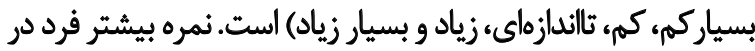

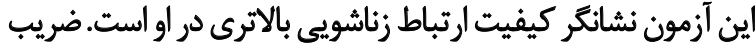

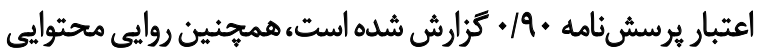

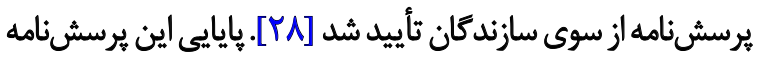

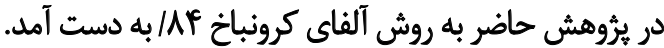

\section{ياقتهها}

همان تونه كه در جدول شماره 1 ملاحظه مى أوده، شاخصهاى

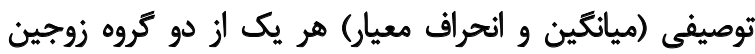

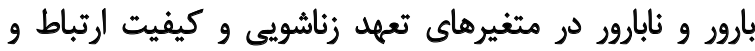

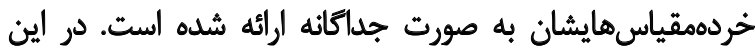

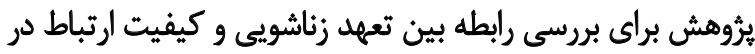

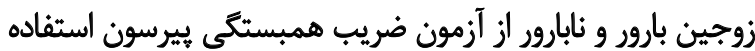
شد كه نتايج آن در ادامه آمده است.

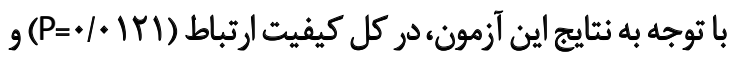

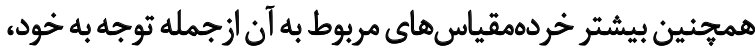

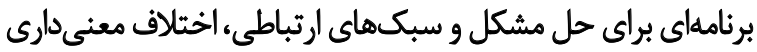

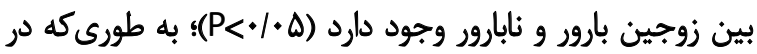

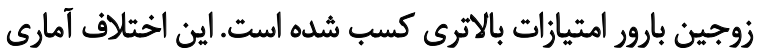

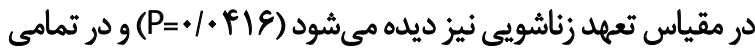

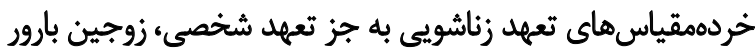

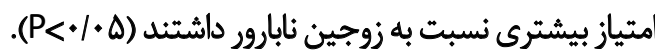

همانكونه كه در جدول شماره Y ملاحظه ميشوده، بين تعهد

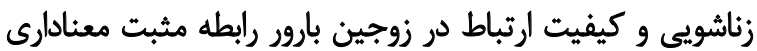

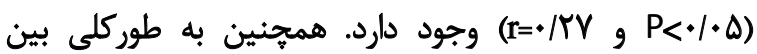

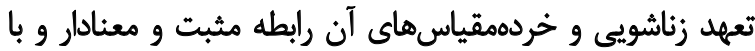

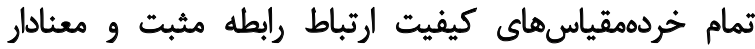

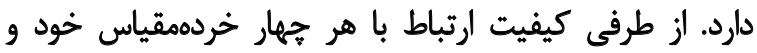

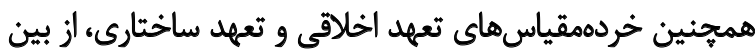

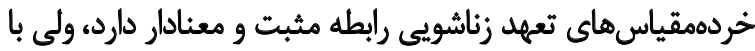
خردهمقياس تعهد شخصى رابطه معنادارى ندارد. همانكونه كه در جدول شماره r ملاحظه مىشود بين تعهد

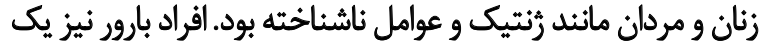

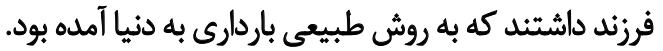

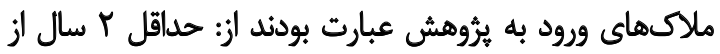

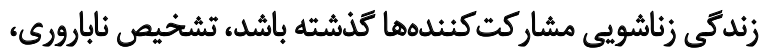

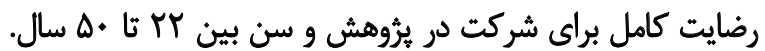

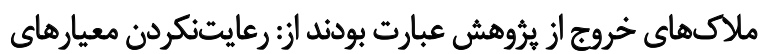

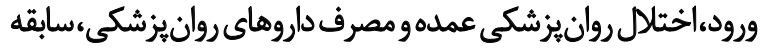

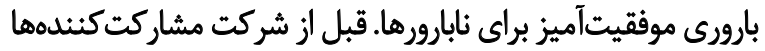

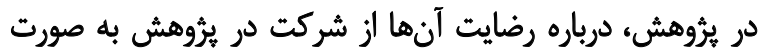

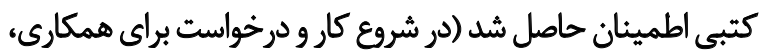

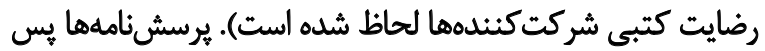

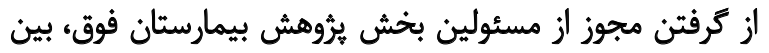

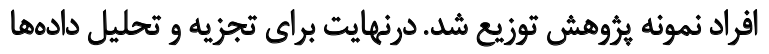

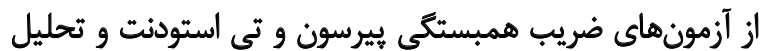
واريانس جندمتغيره استفاده شد.

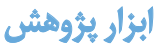

\section{يرسش نامه تعهدز ناشويى}

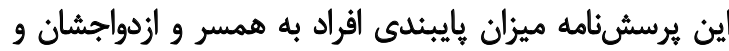

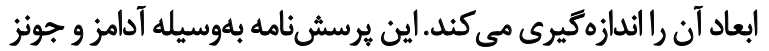

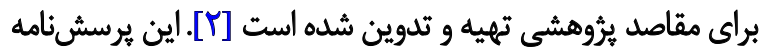

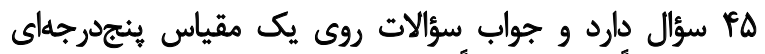

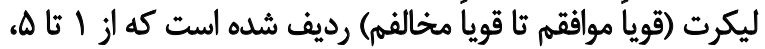

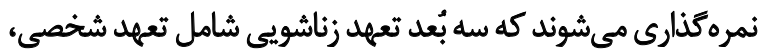

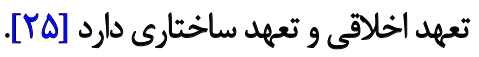

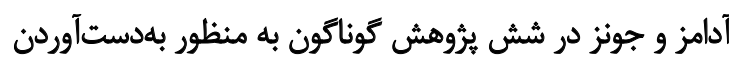

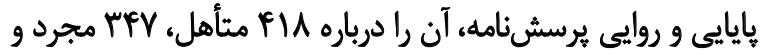

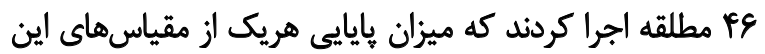

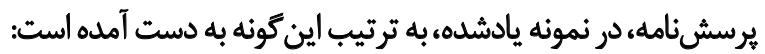

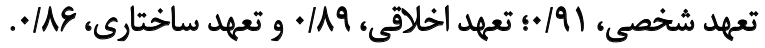

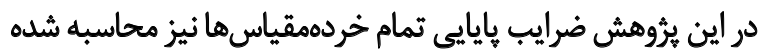

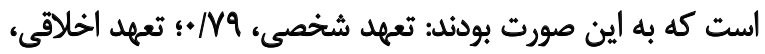

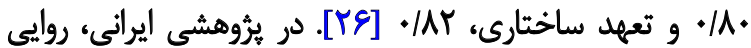

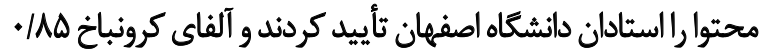

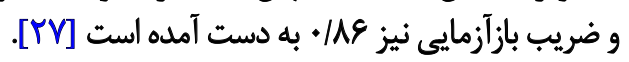
نمره آزمون از جمع نمرات خردمديقياسها به دست مى آيد كه

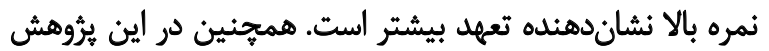

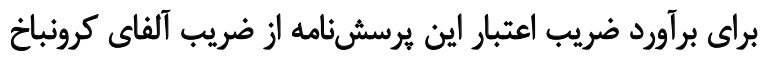

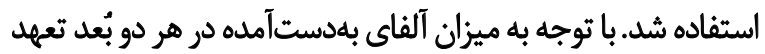

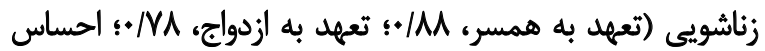

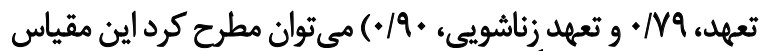

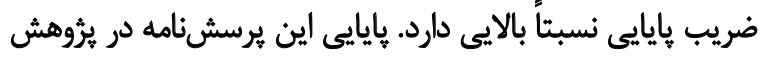


جدول ا. شاخص هاي توصيفى متغيرهاى يُّوهش

\begin{tabular}{|c|c|c|c|}
\hline آزمون آمارى تى استودنت & ميانكين +انحر آف معيار & & متغير \\
\hline$t=r / 199 \vee, d f=14, P=* / * r q$. & $\begin{array}{l}19 / 19 \pm r / q 8 \\
W \cdot V \pm r / M\end{array}$ & نابارور & توجه به خود \\
\hline$t=1 / 9 r \Delta f, d f=1 Q, P=.1 . \Delta f r$ & 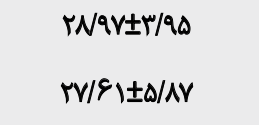 & نابارور & توجه به همسر \\
\hline$t=r / T a \Delta \%, d f=19 \Lambda_{6} P=+1+T T Y$ & $\begin{array}{l}r \cdot 1 \cdot \& \pm T / V E \\
M / E Y \pm \Delta / r r\end{array}$ & نابارور & برنامه براى حل مشكل \\
\hline$t=r / \cdot 19, d f=14, P=\cdot 1 \cdot r q \Lambda$ & $\begin{array}{l}\Delta F / I V \pm N / \Delta \\
\Delta V / r \pm \mid r / q .\end{array}$ & نابارور & سبكهاى ارتباطى \\
\hline$t=r / \Delta r r r, d f=\left|9 \Lambda_{c} P=. / \cdot\right| r \mid$ & $\begin{array}{l}\left|K Y V^{E} \pm\right| V / \cdot 1 \\
\| Q / 1 E \pm Y Y / A V\end{array}$ & باريارور & كيفيت ارتباط \\
\hline$t=r f / r r \cdot r, d f=14, P=* 1 \ldots .1$ & 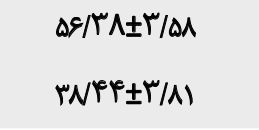 & نابارور & تعهد شخصى \\
\hline $\mathrm{t}=r / f V \& \Delta_{c} \mathrm{df}=19 \mathcal{A}_{c} \mathrm{P}=\cdot / \cdot \mathrm{rer}$ & $\begin{array}{l}r N Y \cdot \pm T / M) \\
r N F Y \pm T(A)\end{array}$ & نابارور & تعهد اخلاقى \\
\hline 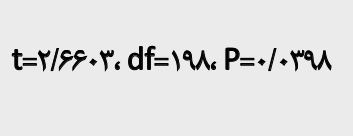 & $\begin{array}{l}m q / f+m / A r \\
r q \cdot f \pm f / n\end{array}$ & نابارور & ت تعهلد ساختارى \\
\hline $\mathrm{t}=\varepsilon / \pi \mathrm{r}+1, \mathrm{df}=\left|q \Lambda_{\varepsilon} \mathrm{P}=+1+\varphi\right| \varepsilon$ & $\begin{array}{l}\mid m / \cdot V \pm \Delta / Y \Psi \\
\mid m / \Lambda \cdot \pm \& / \Psi)\end{array}$ & بالبارور & تعهل زناشويع \\
\hline
\end{tabular}

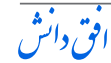

جدول r. ضرايب همبستكى بين تعهل زناشويى و كيفيت أرتباط و زيرمقياسهاى آنها در زوجين بارور

\begin{tabular}{|c|c|c|c|c|c|c|c|c|c|}
\hline زناشيويى تعهد & تساختًارى & اخلاقي تعهد & شخصهى & كيفيت ارتباط & سبكهاى ارتباطي & برنامه براى & توجسي بل & توجه به خود & \\
\hline - & - & - & - & - & - & - & 1 & | IE\&" & توجه به همسر \\
\hline- & - & - & - & - & - & 1 & $.14 A^{\circ}$ &.$/ \Delta A^{*}$ & برنامه براى حل هشكل \\
\hline- & - & - & - & - & 1 & $.189^{\circ}$ & $.18 Y^{*}$ &.$/ \Delta T^{*}$ & سبكهاي ارتباطي \\
\hline - & - & - & - & 1 & $.19 r^{*}$ &.$/ A r *$ & $\cdot|A|^{*}$ & $\cdot M * *$ & كيفيت ارتباط \\
\hline - & - & - & 1 & .1 .0 & .1 .1 & .1 .8 & .1 .1 & $.1+r$ & تعهل شخَصى \\
\hline - & - & 1 & $\cdot / r \cdot *$ &.$/ r \Delta^{*}$ &.$/ 4 \Delta^{*}$ &.$/ R A^{*}$ & $\cdot / T^{*}$ &.$/ M A^{*}$ & تعهد اخلاقى \\
\hline- & 1 & $. / 1 P=*$ & ./rq** & $\cdot / \pi *$ &.$/ M * *$ & $.11 A^{* *}$ &.$/ r \Delta^{*}$ & $+\pi *$ & تعهل ساختارى \\
\hline 1 & . /get & $\cdot(\Delta)^{*}$ & $\cdot / \mathrm{A}^{* *}$ & $\cdot / T+*$ &.$/ T^{* * *}$ & $. / M=*$ & $\cdot / \mathrm{A}^{* *}$ &.$/ F *$ & تعهل زناشوييى \\
\hline
\end{tabular}


جدول ب. ضرايب همبستكى بين تعهد زناشويى و كيفيت أرتباط و زيرمقياسهاى آنها در زوجين نابارور

\begin{tabular}{|c|c|c|c|c|c|c|c|c|c|}
\hline زناشوييى & ساختارى تعهد & تخهيد & شخحصى تُهد & كيفيت ارتباط & سبكهاي الرتباطي & برنامه مشراى & توجه به & توخوجه به & \\
\hline- & - & - & - & - & - & - & 1 & $.19 Y^{\circ}$ & توجه به همسر \\
\hline- & - & - & - & - & - & 1 & .10 & .18. & برنامه براى حل مشكل \\
\hline- & - & - & - & - & 1 &.$M M^{*}$ & . $\mid A r^{*}$ & $+10 *$ & سبكهاى ارثباطى \\
\hline- & - & - & - & 1 &.$/ 90^{*}$ & ./Am* & $\cdot / A r^{*}$ & $\cdot / M{ }^{*}$ & كيفيت ارتباط \\
\hline- & - & - & 1 & $+1+1$ & $.1 \cdot 9$ & +1.8 &.$/ N F$ & $\% \vee r$ & تعهد شخصى \\
\hline- & - & 1 &.$/ 4 \cdot$ & 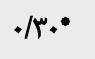 &.$/ 4 \Delta^{*}$ &.$/ T \Delta^{*}$ &.$/ r$ &.$/ \pi$ & تعمد اخلاقى \\
\hline- & 1 & $+/ 1 V^{* *}$ &.$/ 7 q * *$ & $\cdot M$ &.$/ T A^{* *}$ & $\cdot M \mathrm{~A}^{* *}$ &.$/ A^{*}$ &.$/ 4 \%$ & تعهد ساختارى \\
\hline 1 & $.109^{\circ}$ & $\cdot / p v^{*}$ & . &.$/ 1 A^{*}$ & $+/ r+*$ & $+/ T T^{*}$ &.$/ 11 \%$ & $. / \pi m=$ & تعهلد زناشويى \\
\hline
\end{tabular}

جدول F. آزمون فرض عادىبودن توزيعها

\begin{tabular}{|c|c|c|c|}
\hline سطح معنادارى & كلموكروف|سميرنوف & كئوه & متغير \\
\hline$\% 1 \% 19$ & $\% A T$ & بارور & \multirow[b]{2}{*}{ تعهل زناشويي } \\
\hline.$/ 1 Y$ & 1.94 & نابارور & \\
\hline$+1.8 v$ & $+1+98$ & 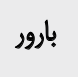 & \multirow{2}{*}{ كيفيت ارتباط } \\
\hline .1 .94 & 1.99 & ثابارور & \\
\hline
\end{tabular}

is

همان Sونه كه از يافتههاى جدول شماره F استنباط مىشود،

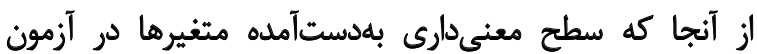

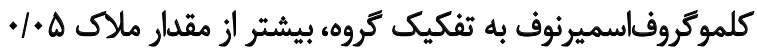

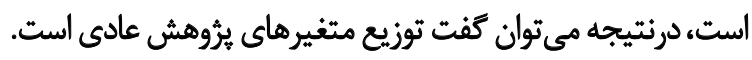
نتايج جدول شماره ه هوياى آن است كه شرط همكنى ماتريس واريائس كوواريانس بهخوبى رئي رايت شده است. نتايج آزمون لامبداي

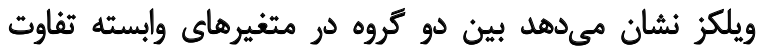

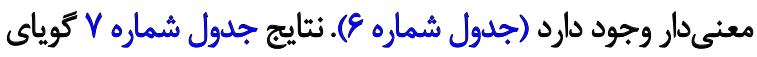

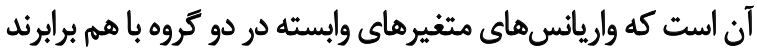
و تففاوت معنى دارى ندارند.

همان زونه كه در جدول شماره 1 ملاحظه مى شود بين دو زروه

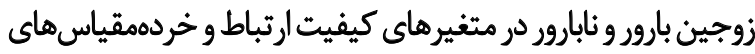

زناشويى و كيفيت ارتباط در زوجين نابارور رابطه مثبت معنادارى

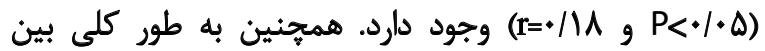

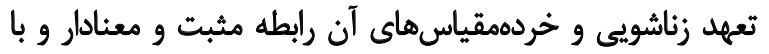

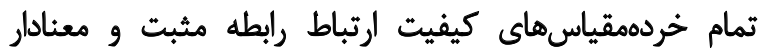

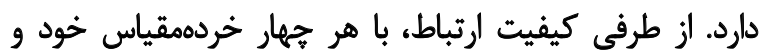

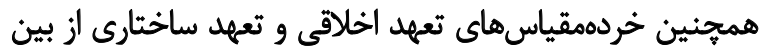

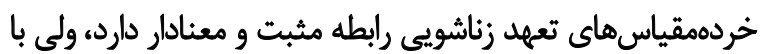

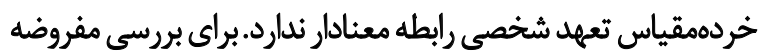

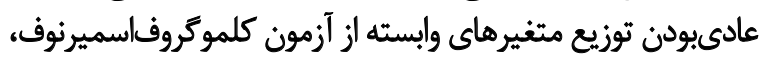

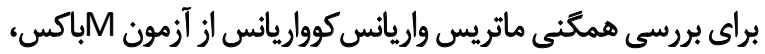

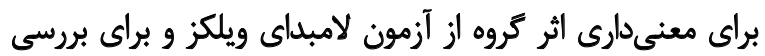

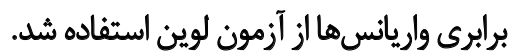

جدول هـ نتايج بررسى همكنى مائريس واريانس كوواريانس

\begin{tabular}{|c|c|c|}
\hline سطح معنادارى & $F$ & باكس M \\
\hline ./rVa & $1 / r 1$ & $r / \Delta S F$ \\
\hline
\end{tabular}

انقّانت 
جدول \&. نتايج آزمون لامبداي ويلكز براى بررسى اثر گروه

\begin{tabular}{|c|c|c|c|}
\hline سطح معنادارى & $F$ & ارزش & أزمون \\
\hline r & F/VED & .1891 & لامبداى ويلكز \\
\hline
\end{tabular}

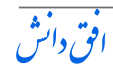

جدول V. نتايج آزمون لوين براى بررسى ييشفرض برابرى واريانسها

\begin{tabular}{|c|c|c|c|c|}
\hline سطح معنادارى & DFY & DFI & $F$ & متغيرها \\
\hline.$/ 148$ & 14 & 1 & V/me & تعهل زناشويى \\
\hline$\cdot N \cdot 1$ & 141 & 1 & $\mathrm{~T} / A \mathrm{AV}$ & كيفيت ارتباط \\
\hline
\end{tabular}

نें

در يُوهش خود كه روى زوجين نابارور لهيستانى انجام شد نشان داد

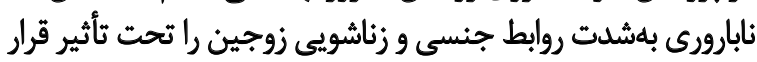

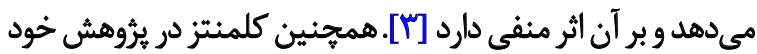

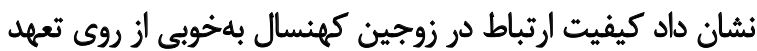

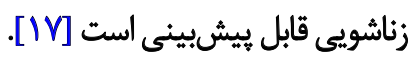

در تبيين يافتههاى مذكور مى توان كفت نابارورى به عنوان

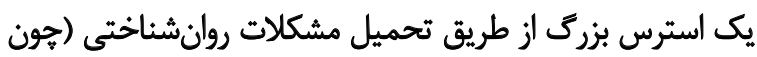

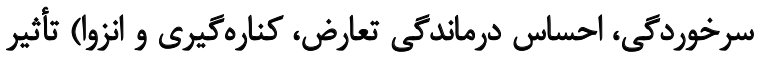

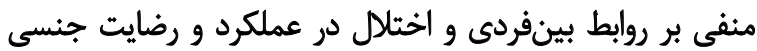

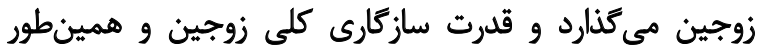

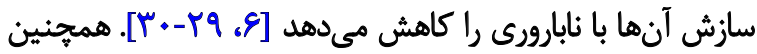

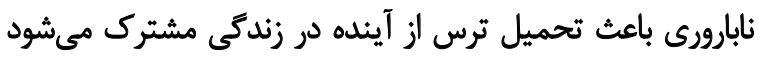

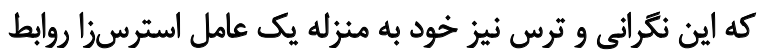

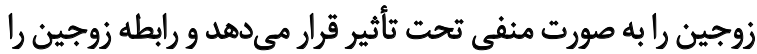

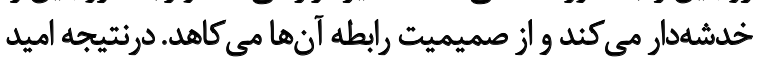

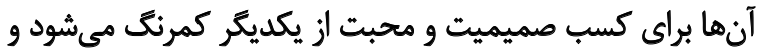

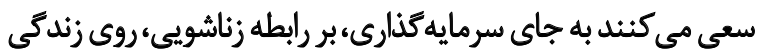

برنامه براى حل مشكل، سبكهاى ارتباطى، توجه به همسر و تعهد

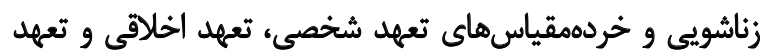

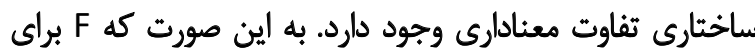

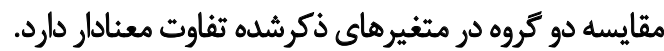

ث

يافته نهايي يُروهش حاضر اين بود كه در بين دو كروه زوجين

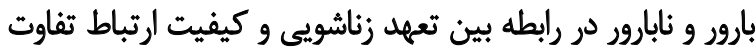

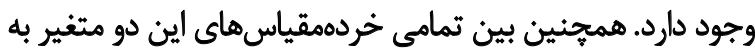

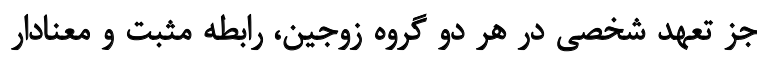

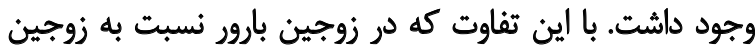

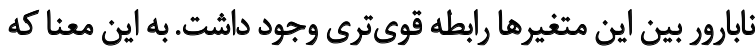

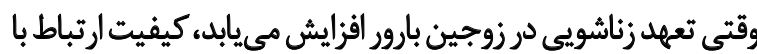

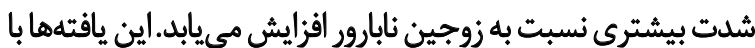

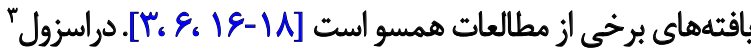

3. Drosdzol

جدول A. نتايج تحليل واريانس براى مقايسه زوجين بارور و نابارور بر اساس نمرههاى كيفيث ارتباط و تعهدزناشويى (درجه آزادى=)

\begin{tabular}{|c|c|c|c|}
\hline معنادارى & $F$ & ميانكين مجذورات & متغير \\
\hline 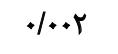 & $\Delta / r V$ & PeT/VA & توجه به همسر \\
\hline$\% 1$ & $\Delta / \& Y$ & $p q . / p T$ & برنامه براي حل مشكل \\
\hline 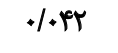 & $s / T \Lambda$ & $\Delta \cdot \mathcal{N} r$ & سبكهاى ارتباطى \\
\hline$+\ldots+1$ & Ir/at & WRT/KG & كيفيت ارتباط \\
\hline$\cdot 1 \cdot+r$ & $v / q$. & $\Lambda \cdot V / M$ & تعهد شخصى \\
\hline$+\infty+\infty$ & NFA & $11 \cdot r / M$ & تعهد اخلاقى \\
\hline.$/ \cdot 18$ & $V / V q$ & ATV/FA & تعهد ساختارى \\
\hline.$\cdot r$ & ID/Ta & $M T q . / 0 T$ & تعهب زناشويى \\
\hline
\end{tabular}

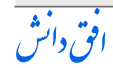




\section{ماحظات اخلاقى \\ يبروى أز أصول اخلاق يُوتش}

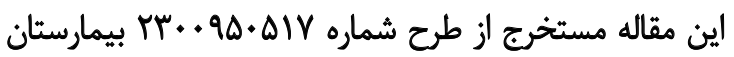
فوقتخصصى بارورى و نابارورى صارم است.

$$
\text { مامي مالب }
$$

هزينههاى اين مقاله به صورت شخصى تأمين شده است.

مشاركت نويسندكان

مجرى طرح و نويسنده مسئول مقاله، ويرايش بيان مسئله و ديكر

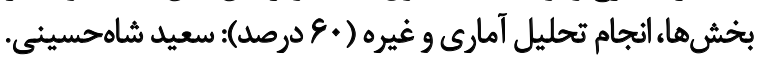

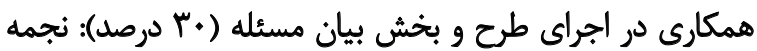

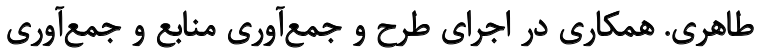

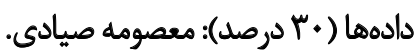

\section{تُارض منأق}

هيجكونه تعارض منافع از سوى نويسندكان بيان نشده است

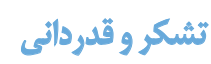

در يايان واجب مي دانيم از جناب آقاى دكتر مسعود غلامعلى

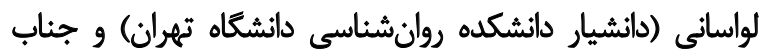

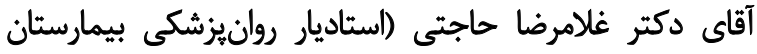

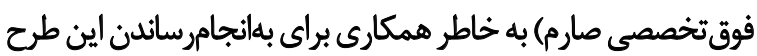
تقدير و تشكر كنيم.
شغلى، تفريحى يا تحصيلى سرمايهذذارى كنند تا كمبودشان را

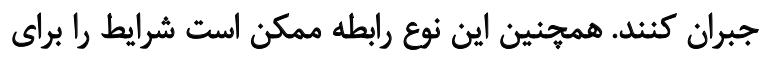

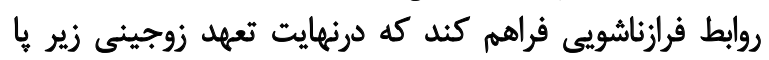

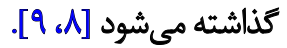

از طرفي به دنبال مشكلات ارتباطى، فشارى كه زوجين براي

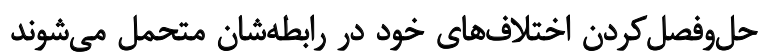

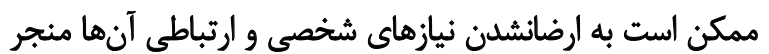

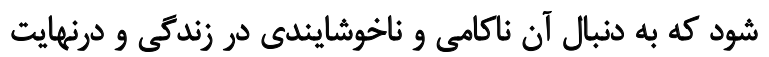

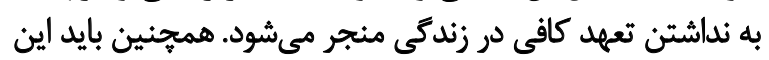

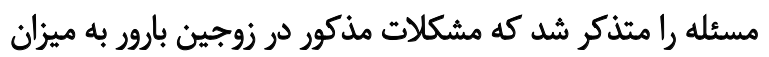

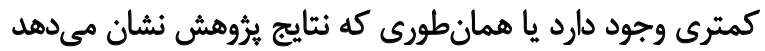

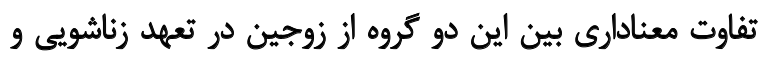

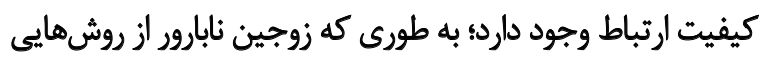

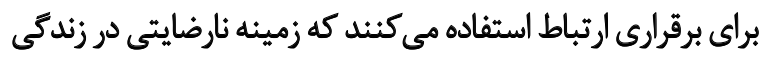
زناشويى آنها را فراهم مى كنياطد.

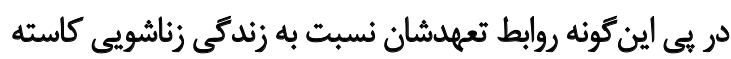

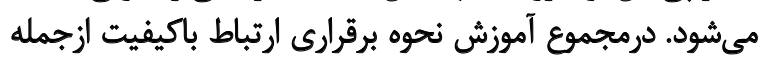

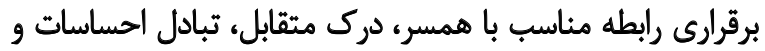

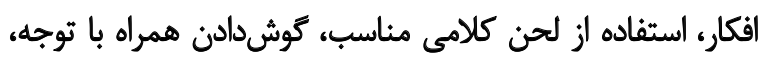

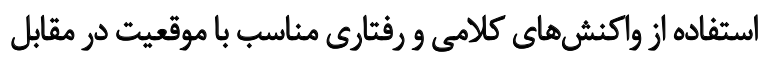

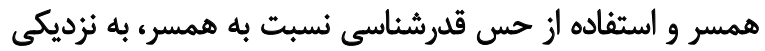

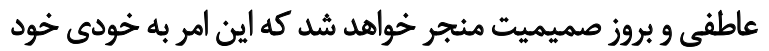

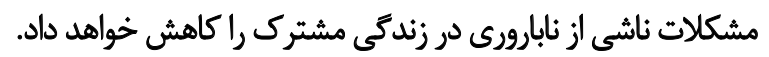

\section{تئيجاكيرى}

در ثايان اين يروهش ميثتوان نتيجه كرفت مسئله نابارورى در

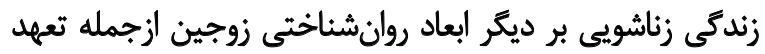

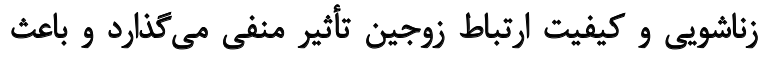

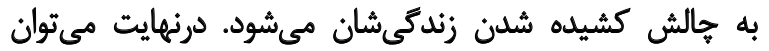

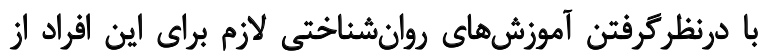

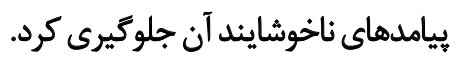

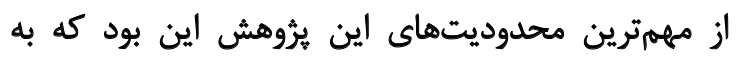

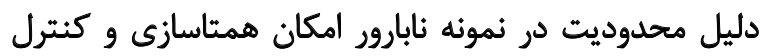

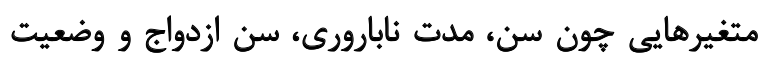

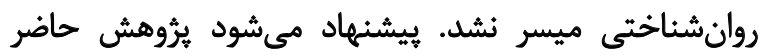

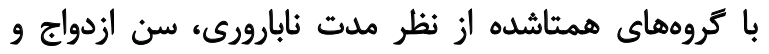

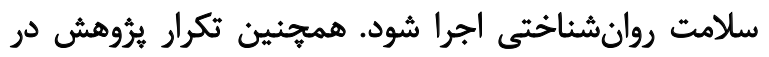

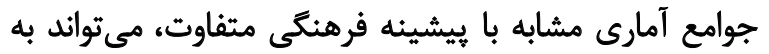

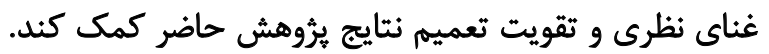

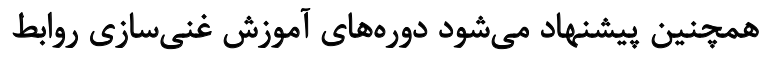

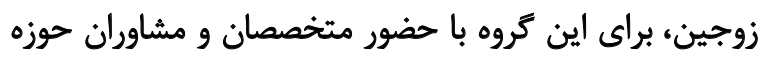

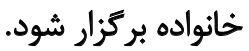




\section{References}

[1] Cunningham FG, Leveno KJ., Bloom SL, Hauth JC, Gilstrap III, Wenstrom KD. Williams Obstetrics. 22 ${ }^{\text {nd }}$ Edition, New York: McGraw Hill; 2005.

[2] Jacobson MH, Chin HB, Mertens AC, Spencer JB, Fothergill A, Howards PP. "ResearchonInfertility:DefinitionMakesaDifference"Revisited. American Journal of Epidemiology. 2017; 187(2):337-46. [DOI:10.1093/aje/ kwx240] [PMID] [PMCID]

[3] Drosdzol A, Skrzypulec V. Evaluation of marital and sexual interactions of Polish infertile couples. The Journal of Sexual Medicine. 2009; 6(12):3335-46. [DOI:10.1111/j.1743-6109.2009.01355.x] [PMID]

[4] Luk BH-K, Loke AY. The impact of infertility on the psychological wellbeing, marital relationships, sexual relationships, and quality of life of couples: A systematic review. Journal of Sex \& Marital Therapy. 2015; 41(6):610-25. [DOI:10.1080/0092623X.2014.958789] [PMID]

[5] Gana K, Jakubowska S. Relationship between infertility-related stress and emotional distress and marital satisfaction. Journal of Health Psychology. 2016; 21(6):1043-54. [DOI:10.1177/1359105314544990] [PMID]

[6] Behdani F, Erfanian M, Jobrani P, Hojat K. [Investigation of the prevalence of depression and factors affecting it in infertile women admitted in Mashhad's Montaseryeh infertility clinic (Persian)]. The Quarterly Journal of Fundamentals of Mental Health. 2004; 6(23-24):141-6.

[7] Aslzaker M, Pourshahbaz A, Bagheri Lankarani N, Mohammadkhani P, Geranmayepour S. [Effects of infertility stress, psychological symptoms, and quality of life on predicting success rate of ivf/icsi treatment in infertile women (Persian)]. Journal of Practice in Clinical Psychology. 2016; 4(4):275-81. [DOI:10.18869/acadpub.jpcp.4.4.275]

[8] Shahsiah M, Bahrami F, Mohebi S. [Investigation of the relationship between sexual satisfaction and marital commitment of couples in Shahreza city (Persian)]. Quarterly Health System Research. 2009; 11(43):233-8.

[9] Weeks G, Treat S. Couples in treatment. New York: Routledge; 2013. [DOI:10.4324/9780203782569]

[10] Sahebdel H, Zahrakar K, Delavar A. [Diagnosis of successful marriage indicators (qualitative research) (Persian)]. Research in Clinical Psychology and Counselings. 2016; 5(2):32-46

[11] Johnson MP, Caughlin JP, Huston TL. The tripartite nature of marital commitment: Personal, moral, and structural reasons to stay married. Journal of Marriage and Family. 1999; 61(1):160-77. [DOI:10.2307/353891]

[12] Abbasi Molid H. [The effectiveness of educationg reality therapy on couples' marital commitment in khomeynishahr (Persian)] [MSc. Thesis]. Isfahan: Isfahan University; 2009.

[13] Givertz M, Segrin C, Woszidlo A. Direct and indirect effects of commitment on interdependence and satisfaction in married couples. Journal of Family Psychology. 2016; 30(2):214-20. [DOI:10.1037/fam0000174] [PMID]

[14] Robinson CD. Differences in marital satisfaction and marital commitment based on theological adherence to and practice of biblically based principles according to ephesians [PhD. dissertation]. California: Alliant International University; 2017.

[15] Ghezelseflo M, Jazayeri R, Bahrami F, Fesharaki RM. The role of relational maintenance behavior and attachment styles in predicting marital commitment. Asian Social Science. 2016; 12(9):223-9. [DOI:10.5539/ ass.v12n9p223]
[16] Mosako J. Commitment and attachment dimensions [PhD. dissertation]. West Lafayette: Purdue University; 2009.

[17] Clements R, Swensen CH. Commitment to one's spouse as a predic tor of marital quality among older couples. Current Psychology. 2000 19(2):110-9. [DOI:10.1007/s12144-000-1007-7]

[18] Amani A, Behzad D. [The effectiveness of schema-therapy on promoting marital commitment and couples' self-esteem (Persian)]. Counseling Research Quarterly. 2012; 11(41):117-33.

[19] Stanley SM, Markman HJ, Whitton SW. Communication, conflict, and commitment: Insights on the foundations of relationship success from a national survey. Family Process. 2004; 41(4):659-75. [DOI:10.1111/ j.1545-5300.2002.00659.x]

[20] Speroff L, Fritz MA. Clinical gynecologic endocrinology and infertility. Philadelphia: Lippincott Williams \& Wilkins; 2005

[21] Haines J, Rifas-Shiman SL, Horton NJ, Kleinman K, Bauer KW, Davison KK, et al. Family functioning and quality of parent-adolescent relationship: cross-sectional associations with adolescent weight-related behaviors and weight status. International Journal of Behavioral Nutrition and Physical Activity. 2016; 13:68. [DOI:10.1186/s12966-016-0393-7] [PMID] [PMCID]

[22] Kouros CD, Papp LM, Goeke-Morey MC, Cummings EM. Spillover between marital quality and parent-child relationship quality: Parental depressive symptoms as moderators. Journal of Family Psychology. 2014; 28(3):315-25. [DOI:10.1037/a0036804] [PMID] [PMCID]

[23] Farajnia S, Hosseinian S, Shahidi S, Sadeghi MS. [Codifying and Examine Psychometrics Properties of Marital Sexual Function Scale (MSFS (Persian)]. Biannual of Journal Applied Counseling. 2014; 4(1):85-102. [DOI:10.22055/JAC.2014.12563]

[24] Litzinger S, Gordon KC. Exploring relationships among communication, sexual satisfaction, and marital satisfaction. Journal of Sex \& Marital Therapy. 2005; 31(5):409-24. [DOI:10.1080/00926230591006719] [PMID]

[25] Ghanbari Hashemabadi BA, Hatami Varzaneh A, Esmaieli M, Farahbakhsh K. [On the Relationship among Parenting Styles, Attachment Styles and Marital Commitment in Arried Female Students of Allameh Tabatabai University (Persian)]. Sociology of Women. 2011; 2(7):39-60.

[26] Adams JM, Jones WH. The conceptualization of marital commitment: An integrative analysis. Journal of Personality and Social Psychology. 1997; 72(5):1177-96. [DOI:10.1037/0022-3514.72.5.1177]

[27] Reynolds J, Mansfield P. The effect of changing attitudes to marriage on its stability. high divorce rates: The state of the evidence on reasons and remedies: Reviews of evidence on the causes of marital breakdown and the effectiveness of policies and services intended to reduce its incidence. Research Series. 1999; 1:1-38.

[28] Khoshkam S. [The Effect of Couple's Relationship Training Course in the Improvement of the Relationship and Mental Health of the Isfahan's Couples (Persian)] [MA thesis]. Isfahan: Isfahan University; 2006.

[29] Drosdzol A, \& Skrypulec V. Depression and anxiety among Polish infertile couple: An evaluative prevalence study. Journal of Psycosomatic Obsterics and Gynecology. 2009; 30(1):11-20. [DOI:10.1080/01674820902830276] [PMID]

[30] Collier F. [When a couple wants a baby: What are the consequences on their sexuality (French)]. 2010; 19(3):170-4. [DOI:10.1016/j.sexol.2010.03.001] 
This Page Intentionally Left Blank 